\title{
Effect of blood transfusion on lipid peroxidation in preterm infants
}

\author{
S P Wardle, J Drury, R Garr, A M Weindling
}

Arch Dis Child Fetal Neonatal Ed 2002;86:F46-F48

See end of article for authors' affiliations

.....................

Correspondence to: Dr Wardle, Neonatal Unit,

Queen's Medical Centre, University Hospital, Nottingham NG7 $2 \mathrm{UH}$

UK; steve.wardle@

mail.qmcuh-tr.trent.nhs.uk

Accepted

11 September 2001

\begin{abstract}
Objective: To see whether there was a link between blood transfusion and lipid peroxidation as measured by urinary malondialdehyde (MDA) concentration in preterm infants.

Methods: Urine samples were collected before and after blood transfusions in preterm infants. Twenty blood transfusion episodes were studied in 12 infants (some infants were studied on more than one occasion). Twenty two infants who had not received a transfusion were used as controls. All infants were preterm and less than $1500 \mathrm{~g}$ birth weight. Urinary MDA was measured using a thiobarbituric acid assay and expressed as $\mathrm{nmol} / \mathrm{mg}$ creatinine.

Results: The median (interquartile range) urinary MDA concentration before transfusion was 9.1 (6.4$12.6) \mathrm{nmol} / \mathrm{mg}$, and was not significantly different from that in the 22 non-transfused infants (11.3 $(7.3-15.6) \mathrm{nmol} / \mathrm{mg}$ ). There was a significant increase 24 hours after transfusion to 14.6 (7.3-23.7) $\mathrm{nmol} / \mathrm{mg}$, but it decreased to $10.1(6.6-15.4) \mathrm{nmol} / \mathrm{mg}$ when measured a median (range) of 6 (3-9) days later.

Conclusions: Blood transfusions were associated with evidence of increased lipid peroxidation. If lipid peroxidation contributes to the pathogenesis of retinopathy of prematurity and chronic lung disease, these results suggest an explanatory mechanism.
\end{abstract}

B lood transfusions are commonly used in the course of neonatal intensive care, and extremely low birthweight infants often receive multiple transfusions. ${ }^{1}$ The number of blood transfusions received has been independently associated with the development of chronic lung disease (CLD) and retinopathy of prematurity ( $\mathrm{ROP}) \cdot{ }^{2-7}$ One explanation for the association is that the sickest infants are likely to receive a greater number of transfusions. There may be a causative link through the release of oxygen derived free radicals. ${ }^{7}$ Blood transfusions may provide excess ferrous iron, which then facilitates formation of the highly reactive hydroxy radical $(\cdot \mathrm{OH})$ from superoxide in the Haber-Weiss reaction:

$$
\begin{aligned}
& \mathrm{O}_{2}^{-}+\mathrm{Fe}^{3+} \rightarrow \mathrm{O}_{2}+\mathrm{Fe}^{2+} \\
& 2 \mathrm{O}_{2}^{-}+2 \mathrm{H}^{+} \rightarrow \mathrm{O}_{2}+\mathrm{H}_{2} \mathrm{O}_{2} \\
& \mathrm{Fe}^{2+}+\mathrm{H}_{2} \mathrm{O}_{2} \rightarrow \mathrm{Fe}^{3+}+\mathrm{OH}^{-}+\mathrm{OH}
\end{aligned}
$$

The reactive hydroxy radical causes lipid peroxidation and therefore cell injury. Preterm infants are particularly susceptible to this effect of excess iron because of low oxidative defences and low levels of iron binding protein. ${ }^{8-12}$

It is impossible to measure free radicals directly in vivo, and it is necessary to rely on the quantification of their reaction products such as protein carbonyls, modified DNA, and lipid peroxidation products. Malondialdehyde (MDA) is the most widely used index of lipid peroxidation ${ }^{13}$ and is easily measured by the thiobarbituric acid reaction. Raised plasma MDA in preterm infants has been associated with the duration of oxygen treatment and ventilator support, ${ }^{14}$ and urinary MDA concentration has been independently associated with oxygen therapy, intraventricular haemorrhage, CLD, and patent ductus arteriosus. ${ }^{15}$ Plasma MDA and urinary MDA correlate reasonably, but urinary MDA increases about 24 hours after a rise in the plasma concentration. ${ }^{16}$

The advantage of urine analysis for MDA is that it is less invasive than blood sampling, and urinary MDA may give a more accurate picture of whole body lipid peroxidation. The effect of blood transfusions on MDA (or other markers of lipid peroxidation) has not previously been studied.

The hypothesis for this study was that lipid peroxidation, as evidenced by urinary MDA concentration, increases following blood transfusion.

\section{METHODS}

Infants were all less than $1500 \mathrm{~g}$ birth weight. They were included in the study at any time during their treatment on the neonatal unit and were all participants in a trial of two different blood transfusion regimens. Infants were divided into two groups: those who were given a blood transfusion and those who had not received any transfusions. Urine was collected as three hour samples. In the transfused group, three urine samples were obtained during the first one to three days before transfusion, then within 24 hours after the transfusion, and a further sample during the next seven days. Urine samples were obtained within 24 hours of the transfusion because it is known that urinary MDA increases about 24 hours after an oxidative insult. ${ }^{16}$ In the other group of infants, only one sample was obtained.

Each transfused infant received $20 \mathrm{ml} / \mathrm{kg}$ packed red blood cells over a four hour period. The indications for blood transfusion were based on the haemoglobin concentration, the infant's clinical dependency (ventilation status, $\mathrm{F}_{\mathrm{IO}_{2}}$ ), and symptoms ascribed to anaemia. Some infants were also transfused as indicated by measurements of peripheral fractional oxygen extraction made using near infrared spectroscopy with venous occlusion. ${ }^{17}$

Urine samples were frozen to $-20^{\circ} \mathrm{C}$ immediately after collection until analysis. The measurement of MDA was based on the method of $\mathrm{Chirico}^{18}$ and as previously described. ${ }^{16}$ Urine

Abbreviations: MDA, malondialdehyde; $C L D$, chronic lung disease $R O P$, retinopathy of prematurity; $I Q R$, interquartile range. 
Table 1 Basic characteristics of the transfused and non-transfused infants

\begin{tabular}{llll}
\hline & $\begin{array}{l}\text { Non-transfused infants } \\
(\mathrm{n}=22)\end{array}$ & $\begin{array}{l}\text { Transfused infants } \\
(\mathrm{n}=12)\end{array}$ & $\mathrm{p}$ Value \\
\hline $\begin{array}{l}\text { Gestational age (weeks) } \\
\text { Birth weight (g) }\end{array}$ & $29(27-31)$ & $27(26-30)$ & 0.051 \\
Postnatal age (days) & $1120(1025-1174)$ & $1060(900-1160)$ & 0.27 \\
Ventilated & $9(6-14)$ & $19(8-42)$ & 0.02 \\
Receiving TPN & $1(5 \%)$ & $6(30 \%)$ & 0.04 \\
Fraction of inspired oxygen & $11(50 \%)$ & $13(65 \%)$ & 0.81 \\
\hline & $0.21(0.21-0.23)$ & $0.25(0.21-0.40)$ & 0.02 \\
Values are median (interquartile range) unless otherwise indicated. The number of infants transfused was 12, \\
but some were studied on more than one occasion so the number of transfusions was 20. The percentages \\
are calculated on the basis of the number of transfusion episodes. \\
TPN, Total parenteral nutrition. \\
\end{tabular}

samples were also assayed for creatinine, and MDA was expressed as $\mu \mathrm{mol} / \mathrm{mg}$ creatinine.

All results were analysed using SPSS (version 6.1) and non-parametric statistics, as urine MDA concentrations are not normally distributed.

Ethical approval was gained from the local paediatric research ethics committee, and written informed parental consent was obtained.

\section{RESULTS}

Table 1 summarises the characteristics of the two groups (transfused and non-transfused infants). Infants who were transfused tended to be older, more immature, and more likely to be ventilated at the time of the measurement. The median (interquartile range (IQR)) MDA concentration before transfusion in the transfused group was 9.1 (6.4-12.6) $\mathrm{nmol} / \mathrm{mg}$. This was not significantly different from that in the 22 non-transfused infants (11.3 (7.3-15.6) nmol/mg, $\mathrm{p}=0.43)$. Median (IQR) urinary MDA concentration rose within 24 hours after transfusion (14.6 (7.3-23.7) nmol/mg) $(\mathrm{n}=20$, $\mathrm{p}=0.03$; median (IQR) change $4.6(-2.87$ to 14.11$) \mathrm{nmol} /$ $\mathrm{mg}$ ). The median (IQR) MDA concentration fell to 10.1 (6.615.4) $\mathrm{nmol} / \mathrm{mg}$ when measured a median (range) of 6 (3-9) days later, and this was not significantly different from the concentration in controls $(\mathrm{p}=0.75)$.

There was no relation between urinary MDA concentration and birth weight $(r=0.25, \mathrm{p}=0.15)$, gestational age $(r=0.09, \mathrm{p}=0.62)$, or postnatal age $(r=0.11, \mathrm{p}=0.48)$. MDA concentration did not correlate with the time since the last transfusion $(r=-0.02, \mathrm{p}=0.9)$. Infants who were ventilated did not have a higher urinary MDA concentration than controls $(\mathrm{p}=0.66)$, and there was no correlation between $\mathrm{FiO}_{2}$ and MDA concentration $(r=0.08, \mathrm{p}=0.62)$.

\section{DISCUSSION}

This study has shown an increase in MDA concentration after a blood transfusion, reflecting an increase in oxygen derived free radical activity. An increase in markers of lipid peroxidation has not previously been shown in preterm infants after blood transfusion.

Transfusions of packed red blood cells may provide excess ferrous iron, ${ }^{7}$ and this may accelerate the reaction between superoxide and hydrogen peroxide, with production of hydroxy radicals (the Haber-Weiss reaction). These oxygen derived free radicals react readily with lipids to cause lipid peroxidation. This is hypothesised to play a role in the development of several of the diseases of prematurity including ROP and CLD. This theory is supported by data that show a relation between transfusions and ROP and CLD. ${ }^{2-6}{ }^{19-22}$ Our data show that there is a rise in urinary MDA concentration after transfusion, indicating a likely causal link between blood transfusion and increased lipid peroxidation.
There are alternative explanations for the relation between the number of transfusions received and the incidence of CLD and ROP. Infants who develop these complications are likely to be the most immature and the most sick, and the association may be related to this. Many factors have been described that are associated with an increased risk of $\mathrm{ROP}^{6}$ and CLD, and these also need to be considered. We have not shown an increase in the risk of transfused infants developing ROP or CLD. Further study is required to determine whether the increase in urinary MDA that we have shown is clinically significant and whether repeated episodes of transfusion result in cellular damage and increased morbidity.

The change in MDA after blood transfusion seems to be genuine. The infants who were transfused tended to be smaller, more immature, and slightly older, although urine MDA concentration in the infants in this study was not related to gestational age, birth weight, or postnatal age. The transfused infants were also more likely to be ventilated and receiving oxygen. This reflects the fact that these criteria were often used to determine whether a transfusion was necessary. Despite this, these infants did not have significantly higher MDA concentrations before transfusion. There are many possible explanations for this. MDA is affected by many variables including oxygen exposure and ventilation requirement. The large variation in MDA concentration within and between individuals reflects the fact that many factors are involved, and this variation may have hidden small differences related to illness severity. Both the study group and the control group were preterm infants, and many from both groups had complications that may have influenced MDA concentration. The change in MDA concentration over the relatively short period of 24 hours in the transfused infants along with the fall after a median of six days to a value that was not higher than the non-transfused controls strongly supports the notion that this change was due to the intervention (blood transfusion). It is not possible to exclude the possibility that some other factor associated with transfusions may be responsible for the change observed, but this seems unlikely.

Other studies have shown relations between markers of lipid peroxidation and complications of prematurity. A raised plasma MDA concentration in preterm infants has been associated with the duration of oxygen treatment and ventilator support, ${ }^{14}$ and an elevated urinary MDA concentration has been independently associated with oxygen therapy, intraventricular haemorrhage, CLD, and patent ductus arteriosus. ${ }^{15}$ This study was not designed, and is not large enough, to examine relations between complications of prematurity and MDA concentration. Further study is required to examine whether the changes shown in infants following blood transfusion relate to differences in clinical outcome.

MDA concentration increased within 24 hours after a blood transfusion was given but then returned to the normal reference range when measured after a longer period after the transfusion. This change is in accordance with the finding that 
the urinary MDA concentration reflects events that occurred about 24 hours earlier. ${ }^{16}$ The observation that the urinary MDA concentration decreased to within the reference range a few days after the transfusion is against the possibility that the observed change in MDA concentration was due to other causes of oxidative stress because these infants were sick, receiving oxygen, and subjected to other factors that may have led to the development of oxygen derived free radicals. It also suggests that the oxidative stress resulting from blood transfusion was relatively short lived.

It may be possible to limit oxidative damage by giving fewer transfusions by using more restrictive transfusion regimens, ${ }^{23}$ alternative methods to predict benefit from transfusion, ${ }^{17}{ }^{24}$ or erythropoietin. ${ }^{20}$ Alternatively whole blood, containing plasma antioxidants rather than packed cells, could be given to preterm infants, ${ }^{22}$ or an antioxidant could be administered at the time of each blood transfusion. Further research is necessary to determine whether it is feasible to attempt to limit injury from oxygen free radicals in preterm infants and thereby improve their outcome.

\section{Authors' affiliations}

S P Wardle, J Drury, R Garr, A M Weindling, Neonatal Unit, Liverpool Women's Hospital, Liverpool, UK

\section{REFERENCES}

1 Strauss RG. Transfusion therapy in neonates. American Journal of Diseases in Children 1991;145:904-11.

2 Cats BP, Tan KEW. Retinopathy of prematurity: review of a four-year period. Br J Ophthalmol 1985:69:500-3.

3 Clark J, Gibbs JAH, Maniello R. Blood transfusion: a possible risk factor in retrolental fibroplasia. Acta Paediatr Scand 1981;70:535-9.

4 Cooke RWI, Clark D, Hickey-Dwyer M, et al. The apparent role of blood transfusions in the development of retinopathy of prematurity. Eur $J$ Pediatr 1993;152:833-6.

5 Sacks LM, Delivoria Papadopoulos M, et al. Retrolental fibroplasia and blood transfusion in very low-birth-weight infants. Pediatrics 1981;68:770-4

6 Shohat M, Reisner SH, Krikler R, et al. Retinopathy of prematurity: incidence and risk factors. Pediatrics 2000;72:159-63.
7 Sullivan JL. Iron, plasma antioxidants, and the 'oxygen radical disease of prematurity'. American Journal of Diseases in Children 1988; 142:1341-4

8 Autor AP, Frank L, Roberts RJ. Developmental characteristics of pulmonary superoxide dismutase: relationship to idiopathic respiratory distress syndrome. Pediatr Res 1976;10:154-8.

9 Haga P. Ceruloplasmin levels and erythrocyte superoxide dismutase activity in small preterm infants during the early anaemia of prematurity. Acta Paediatr Scand 1981;70:861-4.

10 Frank L, Groseclose EE. Preparation for birth into an $\mathrm{O}_{2}$-rich environment: the antioxidant enzymes in the developing rabbit lung. Pediatr Res 1984; 18:240-4

11 Frank L, Sosenko IRS. Prenatal development of lung antioxidant enzymes in four species. J Pediatr 1987;1 10:106-10.

12 McElroy MC, Postle AD, Kelly FJ. Catalase, superoxide dismutase and glutathione peroxidase activities of lung and liver during human development. Biochim Biophys Acta 1992;1117:153-8.

13 Draper HH, Hadley M. Malondialdehyde determination as index of lipid peroxidation. Methods Enzymol 1990;186:421-31.

14 Inder TE, Graham P, Sanderson K, et al. Lipid peroxidation as a measure of oxygen free radical damage in the very low birthweight infant. Arch Dis Child 1994;70:107-11.

15 Schlenzig J-S, Bervoets K, von Loewenich V, et al. Urinary malondialdehyde concentration in preterm neonates: is there a relationship to disease entities of neonatal intensive care? Acta Paediatr 1993:82:202-5.

16 Drury JA, Nycyk JA, Cooke RWI. Comparison of urinary and plasma malondialdehyde in preterm infants. Clin Chim Acta 1997;263:177-85.

17 Wardle SP, Crawley E, Yoxall CW, et al. Peripheral oxygenation and anaemia in preterm babies. Pediatr Res 1998;44:125-31.

18 Chirico S. High performance liquid chromatography-based thiobarbituric acid tests. Methods Enzymol 1994;233:314-18.

19 Cooke RWI, Drury JA, Yoxall CW, et al. Blood transfusion and chronic ung disease in preterm infants. Eur J Pediatr 1997;156:47-50.

20 Williamson P, Griffiths G, Norfolk D, et al. Blood transfusions and human recombinant erythropoietin in premature newborn infants. Arch Dis Child 1996;75:F65-8.

21 Griffiths G, Lall R, Chatfield S, et al. Randomised controlled double blind study of recombinant erythropoeitin in the prevention of chronic lung disease. Arch Dis Child Fetal Neonatal Ed 1997:76:190-2.

22 Silvers KM, Gibson AT, Russell JM, et al. Antioxidant activity, packed cell transfusions, and outcome in premature infants. Arch Dis Child Fetal Neonatal Ed 1998;78:F214-19.

23 Bifano EM, Miggiani WF, Parker PR. Impact of transfusion guidelines on transfusion practice in premature infants [abstract]. Pediatr Res 1994;35:216A

24 Alverson DC. The physiologic impact of anemia in the neonate. Clin Perinatol 1995;22:609-25. 